\title{
Satisfaction with telephone advice from an accident and emergency department: identifying areas for service improvement
}

\author{
Anita Patel, Jeremy Dale, Robert Crouch
}

\begin{abstract}
Objectives-Members of the public often telephone general practice, accident and emergency departments, and other health services for advice. However, satisfaction related to telephone consultation has received relatively little attention. This study aimed to describe the views of callers to an accident and emergency department who expressed any element of dissatisfaction about their telephone consultation. This was part of a larger study intended to help identify areas for service improvement.

Methods-A telephone consultation record form was used to document details of advice calls made to the accident and emergency department over a three month period. Callers who provided a telephone number were followed up within 72 hours. The interviews were tape recorded, transcribed, and explored using content analysis for emerging themes related to dissatisfaction.
\end{abstract}

Results-203 callers were contacted within 72 hours of their call, of which $197(97 \%)$ agreed to participate. $11(5.6 \%)$ expressed global dissatisfaction, and a further 34 (17\%) callers expressed at least one element of dissatisfaction at some point during the interview. Sources of dissatisfaction fell into four broad categories, each of which included more specific aspects of dissatisfaction: $36(80 \%)$ callers were dissatisfied with advice issues, 31 (69\%) with process aspects, such as the interpersonal skills of the staff member who took the call, 23 (51\%) due to lack of acknowledgement of physical or emotional needs, and $11(24 \%)$ due to access problems.

Conclusion-This study supports the findings of other work and identifies three issues for particular consideration in improving the practice of telephone consultation: (a) training of health professionals at both undergraduate and specialist levels should cover telephone communication skills, (b) specific attention needs to be given to ensuring that the information and advice given over the phone is reliable and consistent, and (c) organisational change is required, including the introduction of departmental policies for telephone advice which should become the subject of regular audit. (Quality in Health Care 1997;6:140-145)
Keywords: telephone advice; patient satisfaction; accident and emergency

\section{Introduction}

The telephone is becoming an increasingly important means of communicating healthcare advice. Its role in general practice, accident and emergency, and other primary care settings is becoming well established. ${ }^{1-3}$ Developing more widespread access to health helplines is currently being considered by the Chief Medical Officer as a means of helping the public to cope with emergencies. ${ }^{4}$ However, few healthcare professionals have been specifically trained to communicate effectively over the phone, and there has been relatively little attention given to user satisfaction.

Satisfaction reflects reactions to salient aspects of the context, process, and outcome of health care, ${ }^{5}$ and is particularly important to consider when developing new services. Dissatisfaction occurs when performance falls below expectations. Understanding user satisfaction should help the development of an agenda for improving the quality of services. Although it has been suggested that as many as $96 \%$ of callers to an accident and emergency department are fully satisfied with the advice they receive, ${ }^{2}$ global measures often mask differences in levels of satisfaction with specific aspects of care. ${ }^{6}$ A recent Australian study examined the public's experiences of telephoning a range of nursing facilities and reported on several areas of difficulty. These included the caller not knowing who they were speaking to, not thinking that they were being treated as individuals, and thinking that calls were dealt with inefficiently. ${ }^{7}$ The applicability of these findings to the National Health Service is unclear.

The current study was undertaken within an accident and emergency department as part of a project aimed at developing an efficient and effective telephone advice service. The project developed through participation of users and providers of the service. ${ }^{8}$

Before the study, as in most accident and emergency departments in the United Kingdom, the giving of telephone advice had been a largely unstructured informal process that lacked accountability. Any member of staff would answer calls from the public and offer advice without any record being kept of the contact, making it difficult to monitor practice and identify areas for service improvement. The initial phase of the project involved the introduction of a systematic approach to handling calls from the public. Switchboard 
staff and accident and emergency receptionists were asked to direct all callers requesting advice from the department to a designated extension. All nursing and medical staff in the department were asked to document each call for advice taken at this extension on a telephone consultation record form which was developed for the project. This enabled the existing demand for the service to be described and callers to be followed up.

An analysis of 597 consecutive documented calls to the department showed that $57 \%$ of calls had been made by a third party and $43.5 \%$ were for children under the age of 15 years. ${ }^{9}$ In all, 149 different presenting complaints were recorded on the record forms, and only $27 \%$ of callers were advised that a visit to accident and emergency was immediately necessary.

In a previous report of the main aspects of this study we noted that of 203 callers who responded in a follow up telephone interview (within 72 hours of their call) to a question about overall satisfaction with the advice they had received from the department, $54.9 \%$ were very satisfied and $31.8 \%$ were satisfied. ${ }^{10}$ However, more detailed analysis of callers' comments given on the caller follow up schedule (appendix) suggested several aspects of the telephone consultation that were causing dissatisfaction. Here we analyse the views of callers who expressed dissatisfaction with any aspect of the telephone consultation, and so identify areas which can be targeted for service improvement.

\section{Methods}

Data collection occurred between 7 November 1993 and 3 February 1994. All callers whose record form included a contact telephone number were identified. A trained interviewer attempted to contact these callers within 72 hours of their call, and invited them to participate in the study. A maximum of three attempts were made to contact each caller at various times of the day to include people with different work and social patterns.

The interview was phrased carefully so as to explain the purpose of the study, obtain the subject's consent to be included in the study, and to ensure that confidentiality was maintained and that the interviewer did not disclose any details about the original call to accident and emergency. The questions on satisfaction were asked within the context of a larger questionnaire that has been described previously. ${ }^{10}$ A standardised instrument was not used as no existing interview schedule suited the aims of the study. Instead, a caller follow up schedule was designed to measure satisfaction and to obtain views on various aspects of a call-for example, access, the information provided, the perceived competence of the member of staff, and the outcome. The interview schedule included a mixture of open and closed questions.

The interviews were tape recorded and transcribed. The data were explored with content analysis for emerging themes related to satisfaction. ${ }^{11}$ Comments referring to dissatisfaction were extracted and coded according to the broad area of service they related to and then according to more specific aspects. These general and specific sources of dissatisfaction were measured according to the number of callers who commented on them. This was done to make the qualitative data more intelligible ${ }^{12}$ and to identify priorities for change.

From data recorded on record forms, the presenting complaints of patients were coded with the international classifications of primary care. ${ }^{13}$ All data recorded on record forms were coded and analysed with the statistical package for social sciences (SPSS).

\section{Results}

Of the 597 calls documented during the study period, 450 included a record of the caller's telephone number. The interviewer was able to contact 203 callers within 72 hours of their call. Of these, 197 (97\%) agreed to participate.

In response to the direct question relating to overall satisfaction with their telephone contact, $62(31.8 \%)$ were satisfied, $107(54.9 \%)$ were very satisfied and $15(7.7 \%)$ were unsure. Only $11(5.6 \%)$ explicitly stated that they were dissatisfied. However, a further 34 (17.2\%) expressed elements of dissatisfaction with at least one aspect of their contact at other points during the interview. (These included 15 $(7.7 \%), 12(6.1 \%)$, and seven $(3.6 \%)$ who had respectively stated that they were unsure, satisfied, and very satisfied, in response to the direct question on overall satisfaction.) These 45 callers and the aspects of dissatisfaction that they described are the subject of this paper.

CHARACTERISTICS OF CALLS IN THE STUDY

Eighteen $(44 \%)$ of the 45 callers were the patients themselves, 13 (32\%) were parents, and the remaining $24 \%$ consisted of children (two), spouses (two), other relatives (four), and unrelated people (two). Twenty seven (60\%) calls related to patients who were female and $18(40 \%)$ were male. There were 32 different presenting complaints covering a wide range of problems. The age of patients ranged between 3 months and 82 years with a mean age of 23.1 years (inter-quartile range 3-30 years). Thirteen $(34 \%)$ calls concerned paediatric patients (aged up to 15 years). Data on age were missing for seven patients.

We compared the characteristics of the these 45 dissatisfied callers with those of the wider sample (reported elsewhere ${ }^{9}$ ) to test for differences between $(a)$ the dissatisfied and satisfied subjects and $(b)$ the interviewed and not interviewed subjects, in terms of patient age (Scheffe multiple range test) and sex, the category of the patient's problem, and the role of the caller $\left(\chi^{2}\right.$ tests). There were no significant differences $(P<0.05)$.

SOURCES OF DISSATISFACTION

The number of specific aspects of dissatisfaction that each caller mentioned during the interview ranged between one and 10 (median three). Sources of dissatisfaction fell into four broad categories: access, process, advice, and physical or emotional needs. The table shows the number of callers whose comments related 
to each of these categories and to the specific aspects within them. Individual comments often related to more than one aspect of dissatisfaction. Nearly three quarters of dissatisfied callers were unhappy with the process by which advice calls were managed and $36(80 \%)$ with the advice offered to them. Statistical analysis of the 197 callers interviewed showed that overall satisfaction was significantly greater $\left(\chi^{2}\right.$ test; $P<0.05)$ for those advised to attend accident and emergency than those who were offered other advice (52 (96\%) and 115 (83\%) respectively). Not being advised to attend accident and emergency also featured as a reason for dissatisfaction in the results of the qualitative analysis (table). Of the four main areas of dissatisfaction, problems with accessibility was the least often mentioned.

\section{Access}

Access problems related to both the hospital switchboard and the accident and emergency department: poor response times from switchboard, being connected to the wrong department, being passed to different extensions within the accident and emergency department, and not being put through to an appropriate member of staff. These aspects are illustrated by the following comments:

"The first time when I asked them, they cut me off. I had to phone up again."

"I was passed around like a yo-yo."

"After waiting half an hour on that line, which happened before when we rang casualty in July, the line went totally dead."

\section{Process}

These included quality of the assessment and the communication skills of staff involved.

"I think she could've been a bit more sympathetic."

"She made me feel as if I was wasting her time."

"She didn't sound very professional."

"I don't know who it was,...it was a lady but I don't know who she was."

"I wouldn't have had to come to casualty if she'd asked me the questions on the phone."
"What I didn't like, as she was speaking to me, she was going "excuse me a minute" and then she was shouting over to someone else to ask if she was saying the right thing - "this lady's 13 weeks, should she be having a ..", you know, that sort of thing."

\section{Advice}

Thirty six (80\%) callers expressed dissatisfaction related to the advice they received.

"She was giving me advice as to what I should do, which was essentially don't come to us, go somewhere else, on the basis of not having a clue as to what was wrong with me."

"I was a little bit annoyed about it really, because I hadn't got any definite answer to what my query was about."

"The nurse couldn't see her and if you can't see the person, you can't say give her so and so, because I wouldn't do it anyway."

"I was hoping that they could tell me something to do at home rather than having to go in."

"I thought to myself straight away, speaking to her, if I wanted to leave it to go to my doctor, why am I phoning the hospital?"

"I didn't get any reassurance from the telephone call that I made."

Physical and emotional needs

Aspects of dissatisfaction of $23(51 \%)$ callers related to uncertainty, pain, or fear at the time of the call, and the failure of the nurse to adequately acknowledge and consider these feelings.

"I was a bit short because I was worried, because I was bleeding and I didn't know what to do, and I'm still bleeding and I still don't know what to do."

"I was quite worried there may be something more worrying wrong."

Of these 45 dissatisfied callers, 33 (73\%) also mentioned aspects of dissatisfaction unrelated to the telephone consultation. These included $25(56 \%)$ callers who expressed dissatisfaction with the accident and emergency department, based on their visit after the telephone contact or on past experiences. Comments were made

Reasons for dissatisfaction: broad categories and the specific descriptions contained within them (total $n=45$ )

\begin{tabular}{|c|c|c|c|}
\hline Access $(n=11)$ & Process $(n=31)$ & Advice $(n=36)$ & Physical or emotional situation $(n=23)$ \\
\hline $\begin{array}{l}\text { Inefficient access (9) } \\
\text { Being passed around to } \\
\text { different telephones (2) }\end{array}$ & $\begin{array}{l}\text { Way dealt with over telephone generally (19) } \\
\text { Interpersonal skills of nurse (7) } \\
\text { Identity and position of staff unknown (5) } \\
\text { Telephone contact, generally (5) } \\
\text { Being asked for personal details (4) } \\
\text { Being unable to speak to doctor (2) } \\
\text { Nurse did not obtain sufficient information (2) } \\
\text { Nurse sounded unprofessional when giving } \\
\text { advice (2) } \\
\text { Nurse unwilling to access patients previous } \\
\text { records (1) } \\
\text { Being misunderstood by nurse (2) }\end{array}$ & $\begin{array}{l}\text { Advice/information given (32) } \\
\text { Limitations of telephone advice (10) } \\
\text { Not being advised to attend accident and } \\
\text { emergency (9) } \\
\text { Receiving insufficient self care advice (8) } \\
\text { Diagnosis over the telephone (3) } \\
\text { Lack of reassurance (1) }\end{array}$ & $\begin{array}{l}\text { Pain/concern/fear (16) } \\
\text { Uncertainty about what to do (8) } \\
\text { Uncertainty about medical problem (6) }\end{array}$ \\
\hline
\end{tabular}


about all aspects of their visit: reception services, waiting times, quality of the consultation, diagnosis, and treatment:

"I was in a lot of pain, and to go to casualty, wait for five hours, to be told they thought I was pregnant and to wait there, when I knew I wasn't-and I wasn't".

Seventeen $(38 \%)$ callers were dissatisfied with aspects of general practice services:

"You have to give them notice in advance that you are going to be ill."

These aspects of dissatisfaction may have influenced callers' views on the telephone advice received from the accident and emergency department.

\section{Discussion}

Telephone contact with an accident and emergency department involves several stages: access (initial contact with the hospital switchboard, transfer to the accident and emergency department); and process (assessment and receit of advice from a member of staff). As this study has shown, from the patient's perspective problems may occur at each of these stages, and at the interfaces between them. Most elements of dissatisfaction seemed to reflect the lack of management and direction that had been given to this part of the accident and emergency department's service. As a result, the service was being provided in an ad hoc manner, lacking consistency and possibly safety, with many patients feeling poorly understood. Analysing these elements of dissatisfaction indicated a range of areas where the effectiveness and efficiency of the service seemed to need improvement.

In interpreting these results, several methodological issues need to be considered. Firstly, the study only investigated the satisfaction of existing users. It is likely that members of the population with language differences and others who have difficulty communicating over the telephone will not be currently using accident and emergency for telephone advice. The importance of providing equitable services-for example, through providing telephone access to interpreters-and the needs within the local population that current services may be failing to meet, must be considered throughout the process of developing service improvements.

Secondly, it seems that some calls were not documented on record forms. ${ }^{9}$ Possible reasons for this include a lack of staff awareness about the departmental policy for documenting all advice calls, or staff resistance to being held more accountable for telephone advice given. The loss of callers from the sample because of non-completion of record forms might have led to underestimation of rates of dissatisfaction, particularly if this occurred more often for calls that nurses thought were dysfunctional.

Thirdly, the period between the subjects' telephone encounter and the follow up interview was limited to 72 hours. This was to minimise the influence of time on satisfaction levels and the chance of recall bias. ${ }^{14}$ However, this methodological constraint, as well as resource constraints meant that many potential subjects could not be contacted. This may have resulted in a bias towards including callers who spent much of their time at home.

\section{PRIORITIES FOR CHANGE}

Access

Certain operational issues relating to the accessibility of the service clearly need further attention. In particular, the time delays involved in callers being transferred from the hospital switchboard to the appropriate accident and emergency department extension should be improved. Consideration could be given to establishing and advertising the availability of a direct advice line to the accident and emergency department for use by members of the public who are uncertain about whether attending accident and emergency is necessary. When possible, the accident and emergency department should ensure that at all times a member of staff is designated to receive advice calls, so that they can be handled in a planned and effective manner.

\section{Process}

There is a need for developing healthcare professionals' telephone consultation skills. All staff who deal with members of the public over the telephone should receive appropriate training, and given the increasing importance telephone consulting is likely to have in the future, telephone consultation skills should also be included within undergraduate curricula. It should include telephone communication skills, covering areas such as listening and questioning skills, with a view to improving the effectiveness of telephone consulting. Such training would help such issues as failing to empathise with and acknowledge callers' needs, which were identified in this study as often leading to caller dissatisfaction. Confidentiality must also be considered, particularly when staff are taking personal details from patients.

\section{Advice}

There is also a need for training in giving advice, including the need to check that callers have understood the advice given before ending a call. Training in more specific aspects, such as alleviating panic or crisis situations, may also be important, enabling staff to deal more effectively with callers who have high levels of anxiety. Although it was beyond the scope of this study to investigate the appropriateness of the advice given, it is clear that many callers were dissatisfied with what they perceived it to have been. There is a need to consider protocols and guidelines to achieving greater reliability and consistency, and advice given over the telephone should be audited.

In attempting to improve services, user dissatisfaction can be used to help pinpoint weaknesses and inefficiencies. However, it also needs to be acknowledged that some users may have expectations that exceed the level of service that can be provided and, as we have reported elsewhere, the expectations and out- 
comes of calls to accident and emergency departments often differ. ${ }^{10}$ An important component of training in telephone consultation should be the development of skills in negotiation and giving information to help patients understand how to make the best use of health services. Also, perhaps the public should receive more education about the role of telephone advice services in the health service, particularly out of hours.

In conclusion, there is considerable potential for developing the provision of telephone advice in the health service. This study indicates how user perspectives could valuably be included, and it seems probable that the issues identified here have general applicability. We have now developed a telephone consultation skills training package and decision support software for nursing staff as part of our response to these needs, evaluations of which will be reported in future publications.

This work forms part of a larger study into telephone consultation both in accident and emergency and general practice which has been funded by the Primary Care Development Fund of has been funded by the Primary Care Development Fund of
South Thames Region and the King's Fund. We thank the nursing and medical staff at King's College Hospital accident and emergency department who took part in this research.
1 Molyneux E, Jones N, Aldom G, Molyneux B. Audit of telephone advice in a paediatric accident and emergency department. F Accid Emerg Med 1994;11:246-9.

2 Egleston CV, Kelly HC, Cope AR. Use of a telephone advice line in an accident and emergency department. BMF 1994; 308:31.

3 Kernohan SM, Moir PA, Beattie TF. Telephone calls to a paediatric accident and emergency department. Health Bull padinb) $1992 \cdot 50 \cdot 233-6$.

4 Calman K. Developing emergency services in the community. Vol 1 emerging conclusions. Department of Health: London, 1 emerging conclusions. Department of Health: London,

5 Pascoe CG. Patient satisfaction in primary health care: a literature review and analysis. Evaluation and Program Planning 1983;6:185-210

6 Locker D, Dunt D. Theoretical and methodological issues in sociological studies of consumer satisfaction with medical care. Soc Sci Med 1987;12:283-92.

7 Farrell G. Telephoning a nursing department: callers' experiences. Nursing Standard 1996:10:34-6.

8 Dale J, Williams S, Crouch R. Development of telephone advice in accident and emergency: establishing the views of staff. Nursing Standard 1995;15:28-31.

9 Crouch R, Patel A, Williams S, Dale J. An analysis of telephone calls to an inner city accident and emergency telephone calls to an inner city acciden

10 Dale J, Crouch R, Patel A, Williams S. Patients telephoning accident and emergency for advice: a comparison of expectations and outcomes. $\mathscr{f}$ Accid Emerg Med 1997;14:21-3.

11 Krippendorf K. Content analysis: an introduction to its methodology. Beverly Hills: Sage, 1980.

12 Mays N, Pope C. Rigour and qualitative research. $B M \mathcal{F}$ 1995;311:109-12.

13 Lamberts $\mathrm{H}$, Wood $\mathrm{M}$, Hofmans-Okkes I, eds. The international classifications of primary care in the European community: with a multi-language layer. Oxford: Oxford University Press, 1993.

14 Carr-Hill RA. The measurement of patient satisfaction. $\mathcal{f}$ Public Health Med 1992;14:236-49.

\section{Appendix: Caller follow up schedule}

Hello, could I speak to please?

Interviewer: If you make contact with the Caller:

This is ............ I work for the accident and emergency department at King's College Hospital. You rang for advice on ..(date).. We are now getting in touch with patients who ring the department for advice to find out how they feel about the service they receive in order to improve the service wherever necessary. Can I ask you some brief questions about your call to our department? It should only take about 5 minutes. Is it convenient to talk now? All the information will remain totally confidential.

Interviewer: If you do not get through to the caller, do not discuss any details and simply explain:

We are carrying out a patient satisfaction survey, so is there a time I can call back to speak with .. ?

Firstly, I would like to ask you about your call.

1. Could you tell me why you needed to call the department?

2. Can you remember if you spoke to a nurse, doctor or both?

Now I would like to ask you a few questions about the advice you received.

3. (i) What were you hoping, if anything, the nurse / doctor would say?

(ii) What were you told to do?

(If told to see doctor) When?

(Unless told to seek immediate care) Do you remember if the nurse told you to call back or attend $A \& E$ if the problem worsened?

(If yes) what were you told to do? 
4. Did you find this advice helpful or unhelpful in any way?

Why was this?

5. Was there anything about this advice that you felt unhappy about?

(If yes) Why was this?

6. What did you do after you made the call?

7. Thinking about how you were dealt with, how do feel about this?

(Prompt) Were you generally happy, unsure or unhappy about the way you were dealt with?

If caller is happy, go to $7 a$

If caller is unsure or unhappy, go to $7 b$

7a. What exactly were you happy with?

Was there anything that you were not completely happy with?

7b. What exactly were you unsure about/not happy with?

Was there anything that you were happy with?

8. Have you any further comments or feelings about your contact with our A\&E department?

9. Did you consider calling your own GP to deal with this medical problem / request before contacting our A\&E department?

(If yes) Why did you not contact him/her?

10. Have you ever contacted this department before for medical advice by telephone?

(If yes) How many times and why?

On these occasions can you remember if you received the advice you were hoping for?

11. Have you visited this $\mathrm{A} \& \mathrm{E}$ department before?

(If yes) How many times and why?

12. Finally, thinking about the call you made to $A \& E$, if you had to express how you felt about the way you were dealt with overall, would you say you were very satisfied, satisfied, unsure or dissatisfied?

Thank you very much for answering these questions. 